\title{
Perfil religioso da população autodeclarada indígena no Brasil: considerações a partir do censo demográfico de 2010
}

\section{Religious profile of the indigenous population in Brazil: some considerations from the 2010 census}

\author{
Claudio Santiago Dias Junior* \\ Ana Paula Verona**
}

\begin{abstract}
Resumo
O perfil religioso da população brasileira é habitualmente construído a partir dos dados do censo demográfico do IBGE. A coleta desta informação é feita pelo IBGE há pelo menos 80 anos. Mesmo com a disponibilidade de informações sobre a população indígena desde o censo demográfico de 1991, ainda não foram realizadas análises sobre o perfil religioso deste subgrupo populacional. Procurando cobrir esta lacuna, o presente trabalho tem como objetivo descrever, a partir do censo demográfico de 2010, o perfil religioso da população autodeclarada indígena no Brasil. Foram analisadas informações de mais de 800 mil pessoas que se declararam indígenas no censo demográfico de 2010 . Os dados do censo demográfico de 2010 mostram que a população indígena é, em sua maioria, cristã, dividida entre católica e evangélica, com um percentual de pessoas sem religião superior ao observado na população em geral do Brasil. Outro ponto importante, mesmo com um percentual bastante reduzido, é a presença de pessoas que se declararam vinculadas às religiões de tradição indígena. Por fim, são apresentados também a situação geográfica, de domicílio, idade e escolaridade desse perfil da população indígena.
\end{abstract}

Palavras-chave: População indígena autodeclarada, Religião, IBGE, Brasil

\begin{abstract}
Using data from the 2010 Brazilian census, this paper aims to describe the religious profile of the indigenous population in Brazil. We analyzed information from more than 800,000 individuals. Our results show that indigenous population is mostly Christian that are separated into Catholics and Evangelicals. Moreover, we found a reduced number of people who declared themselves belonging to indigenous traditional religions. Finally, we present the religious profile of the indigenous population according to region, place of residence, age, and schooling.
\end{abstract}

Keywords: Indigenous Population, Religion, IBGE, Brazil

Artigo recebido em 15 out. 2014 e aprovado em 09 dez. 2014.

${ }^{*}$ Doutor em Demografia, Professor Adjunto III, Departamento de Sociologia - UFMG. País de origem: Brasil.

E-mail: claudio.austin@gmail.com

** Doutora em Demografia, Professora Adjunta I, Departamento de Demografia - CEDEPLAR/UFMG - País de origem: Brasil. E-mail: anapaulaverona@gmail.com 


\section{Introdução}

O campo religioso brasileiro vem passando por profundas transformações nas últimas décadas. De acordo com dados do Instituto Brasileiro de Geografia e Estatística (IBGE), em 1940 quase 96\% dos brasileiros de declararam católicos. Esse número caiu para quase 64,6\% em 2010 (COUTINHO; GOLGHER, 2014; ALVES et al, 2012).

A redução no número de católicos foi resultante, dentre vários fatores, do aumento dos indivíduos que se declararam evangélicos e sem religião. Para ilustrar, em 1940 o número de evangélicos era de 2,6\% e sem religião 0,6\%. Em 2010 esses números passaram para 22,2\% e 8\% respectivamente (COUTINHO; GOLGHER, 2014; ALVES et al, 2012).

Uma transformação de tamanha magnitude no campo religioso pode causar importantes mudanças nas componentes demográficas, a saber, fecundidade, mortalidade e migração, além de impactar aspectos como escolaridade, trabalho, saúde, renda, dentre outras variáveis socioeconômicas. Tais mudanças são possíveis de ocorrer porque a religião pode impactar, de maneira direta ou indireta, comportamentos individuais e de grupos, que têm consequências diretas em diversas esferas da vida social (VERONA, 2011; SMITH, 2003).

De uma maneira geral, a demografia da religião é um campo recente no Brasil. Alguns estudos realizados mostram possíveis associações entre religião e mortalidade materna (VERONA et al, 2010) religião e fecundidade (VERONA; DIAS JÚNIOR, 2012; OGLAND et al, 2010; MCKINNON; POTTER; GARRARDBURNETT, 2008 ), religião e iniciação sexual de adolescentes (VERONA, 2010; OGLAND et al, 2010), religião e aborto (OGLAND; VERONA, 2014), religião e renda (POTTER; AMARAL;E WOODBERRY, 2014), dentre outros aspectos.

Mesmo com o recente aumento de estudos na área da demografia da religião no Brasil, o que se observa é a ausência do componente indígena nas análises da 
demografia da religião. Tal ausência é simbolicamente forte, pois apesar de ser um grupo pequeno numericamente, apresenta componentes extremamente ricos em termos religiosos e é, provavelmente, um dos subgrupos populacionais mais vulneráveis às mudanças religiosas, com perdas de valores culturais incalculáveis (WRIGHT, 2004).

A partir destas constatações, o presente trabalho tem como objetivo, descrever, a partir do censo demográfico de 2010, o perfil religioso da população autodeclarada indígena no Brasil, segundo algumas variáveis socioeconômicas e demográficas. Com isto, espera-se contribuir para o conhecimento deste subgrupo populacional ainda pouco estudado no âmbito da demografia da religião no Brasil e permitir futuras análises que os incluam.

Para a realização das análises dos dados, foi utilizado o programa estatístico SPSS 15 .

\section{População autodeclarada indígena no Brasil}

A coleta de informações sobre os indígenas no Brasil pelo IBGE começou em 1991, com a inclusão da categoria "indígena” na variável cor ou raça. Tal questão foi mantida no Censo de 2000. No Censo de 2010, além da tradicional questão sobre cor ou raça do indivíduo, foram acrescentadas questões referentes à etnia, língua falada e se a pessoa se considerava indígena (última questão para quem não respondeu ser indígena no quesito cor ou raça). Além disso, em 2010 as questões referentes à cor ou raça foram incluídas no questionário do universo ${ }^{1}$ (IBGE, 2012; PAGLIARO; AZEVEDO; SANTOS, 2005).

\footnotetext{
${ }^{1} \mathrm{O}$ censo demográfico do IBGE trabalha com dois tipos de questionário. O questionário da amostra, que é mais detalhado, apenas uma pequena parcela da população responde, e o questionário do universo, que é bem mais simplificado, toda a população do país responde. $\mathrm{O}$ que aconteceu no censo de 2010 é que os quesitos referentes à raça ou cor e os quesitos sobre os indígenas, foram alocadas no questionário do universo, com o objetivo, dentre outros, de diminuir os problemas referentes à amostragem que sempre estiveram presentes nos estudos sobre os indígenas que utilizavam os dados do censo. Por outro lado, o IBGE retirou do banco de dados da amostra, disponibilizado para a população em geral, todas as novas questões sobre a população indígena. Tal fato impede o uso destas questões.
} 
Segundo os dados dos três censos demográficos que utilizaram a categoria “indígena” na variável cor ou raça, a autodeclarada população indígena no Brasil era de 294.131 pessoas em 1991. Este número subiu para 734.127 pessoas em 2000, passando para 817.963 em 2010². Pode-se perceber que no período de 1991 a 2010 houve um acréscimo de 523.832 pessoas que se autodeclararam indígenas, totalizando um aumento de 278\% (IBGE, 2012; PAGLIARO; AZEVEDO; SANTOS, 2005).

A população autodeclarada indígena no Brasil em 2010 se concentrava, basicamente, na região Norte $(37,4 \%)$, seguida pela região Nordeste $(25,5 \%)$. A região com o menor percentual é a região Sul (9,2\%), seguida pela região Sudeste (12\%) e região Centro-Oeste (16\%). Em relação ao local de residência, quase 62\% da população autodeclarada indígena residia em áreas rurais. Praticamente a metade da população indígena era do sexo masculino e 63\% tinha até 29 anos de idade. É importante salientar que entre os indígenas com 15 anos e mais de idade, quase $67 \%$ tinham até o ensino fundamental incompleto.

Outro ponto importante são as condições de vida da população autodeclarada indígena brasileira. Mesmo em áreas onde essa população indígena é maioria, seus indicadores sociais são bem piores quando comparados com outros subgrupos populacionais, como os brancos e negros. Por exemplo, as taxas de mortalidade infantil são muito mais elevadas e possuem pouco acesso a bens e serviços, como esgoto, água tratada e luz elétrica (DIAS JÚNIOR et al, 2010).

\footnotetext{
${ }^{2}$ O número de indígenas em 2010 apresentado neste artigo não inclui os indivíduos que não se classificaram como indígenas, mas se sentem enquanto tal. Ao juntar essa população temos o total de 896.917 indígenas. Tal decisão se deve ao fato de não ser possível, através do banco de dados da amostra, ter acesso a essas informações.
} 


\section{Perfil religioso da população autodeclarada indígena no Brasil}

\subsection{Denominações religiosas entre a população autodeclarada indígena no Brasil}

A variável religião no censo demográfico de 2010 apresenta uma ampla categorização (ver anexo 1). Para a realização deste trabalho a variável religião foi recategorizada da seguinte maneira: católico, evangélico, tradições indígenas, outras religiões e sem religião.

De acordo com o Gráfico 1, a população autodeclarada indígena é majoritariamente católica, apesar de apresentar um percentual menor (10\%) se comparado com a população total do Brasil (IBGE, 2012). Por outro lado, tanto os evangélicos quanto os indivíduos sem religião apresentaram percentuais superiores aos observados na população brasileira (IBGE, 2012). É importante destacar também a presença de religiões de tradição indígena, apesar de um percentual bastante reduzido quando comparado com as religiões católica e evangélica. De uma maneira geral, a população indígena residente no Brasil é majoritariamente cristã, com um percentual significativo de pessoas sem religião.

\section{Gráfico 1 - Denominação religiosa entre a população autodeclarada indígena no Brasil (\%) 2010}

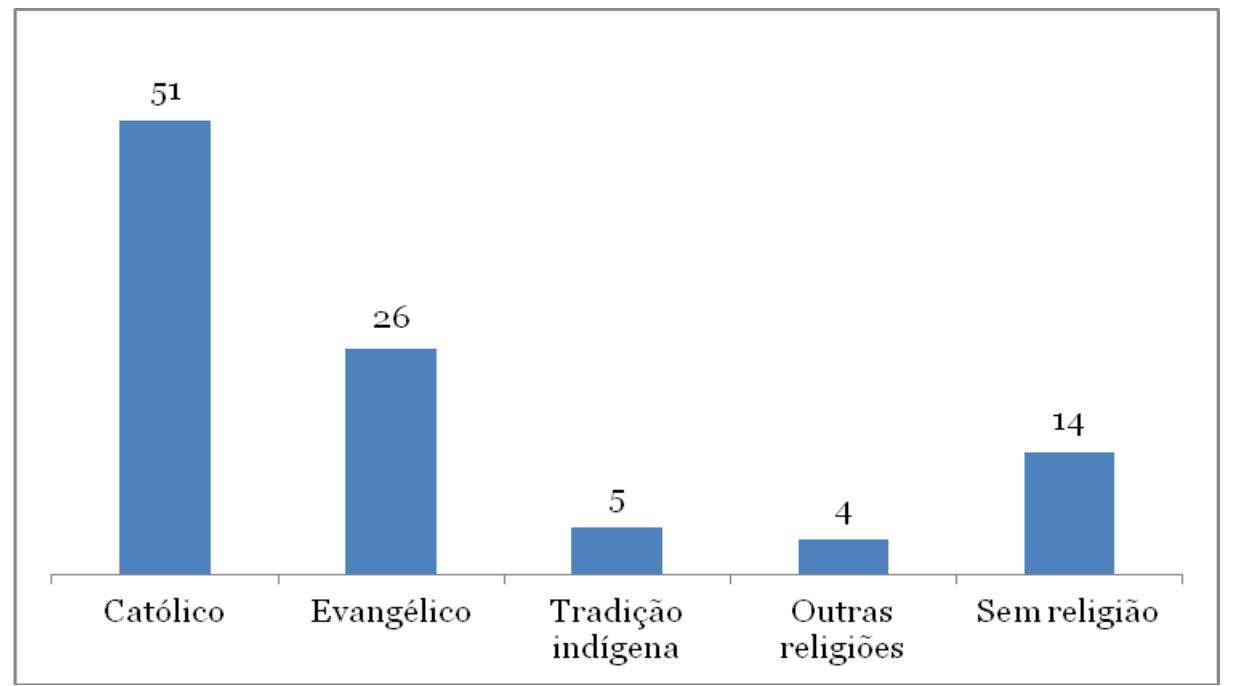

Fonte: Censo Demográfico 2010, IBGE. 


\section{a. Religião e distribuição geográfica entre a população autodeclarada indígena no Brasil}

Ao separarmos os dados segundo as grandes regiões geográficas, observamos algumas particularidades regionais interessantes. De acordo com o Gráfico 2, pode-se perceber que a região Nordeste é o lugar que concentra o maior percentual de indígenas católicos. Na região Centro-Oeste a população de católicos e evangélicos é quase a mesma, sendo que nesta mesma região é onde se concentra o maior percentual de indígenas sem religião, seguido pela região Norte. Na região Norte se encontra o maior grupo que se declarou seguidores de religiões de tradição indígena.

\section{Gráfico 2 - Denominação religiosa entre a população autodeclarada indígena segundo grande região (\%) 2010}

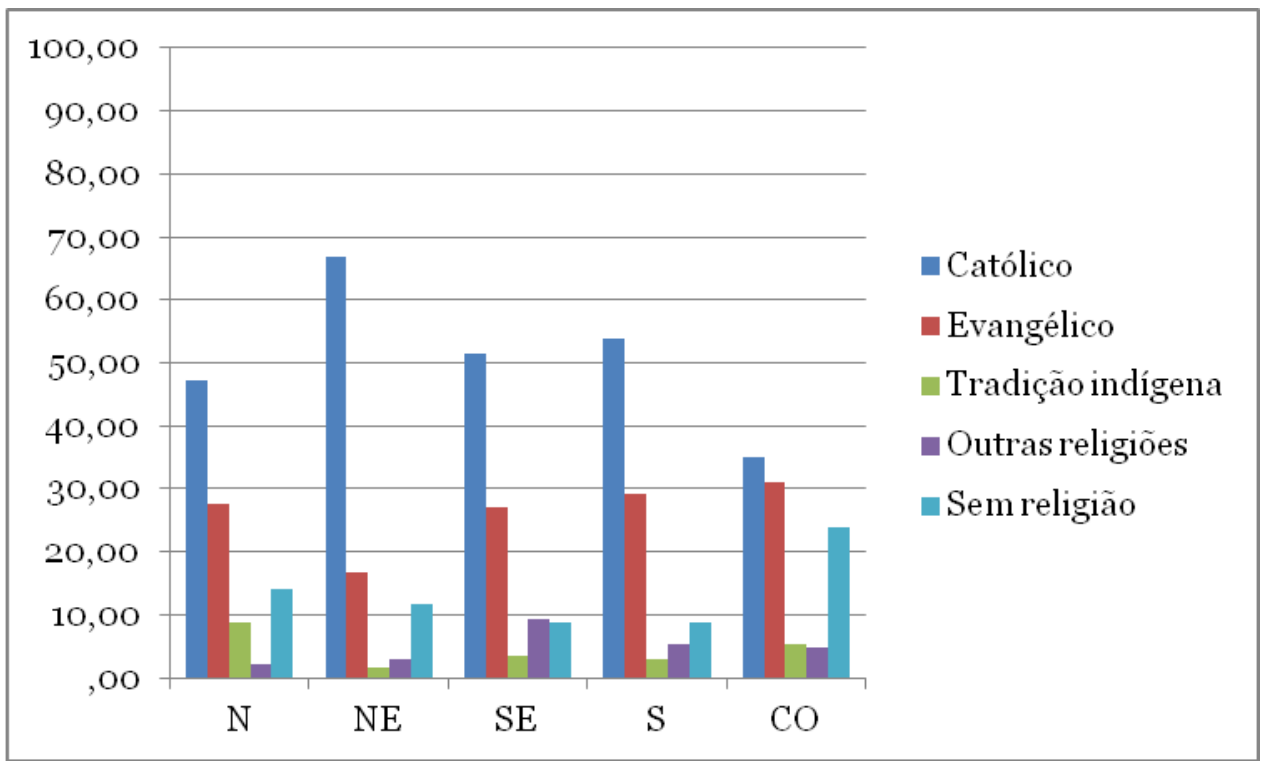

Fonte: Censo Demográfico 2010, IBGE. 
Ao desagregarmos a população autodeclarada indígena segundo o local de residência, se urbano ou rural (Gráfico 3), observa-se um comportamento bastante interessante. Como esperado, indivíduos com religiões de tradição indígena estão, quase que na totalidade, nas áreas rurais, uma vez que a maioria das terras indígenas estão nesses locais. O que chama a atenção é o grande percentual de indígenas sem religião na área rural.

\section{Gráfico 3 - Denominação religiosa entre a população autodeclarada indígena segundo local de residência (\%) 2010}

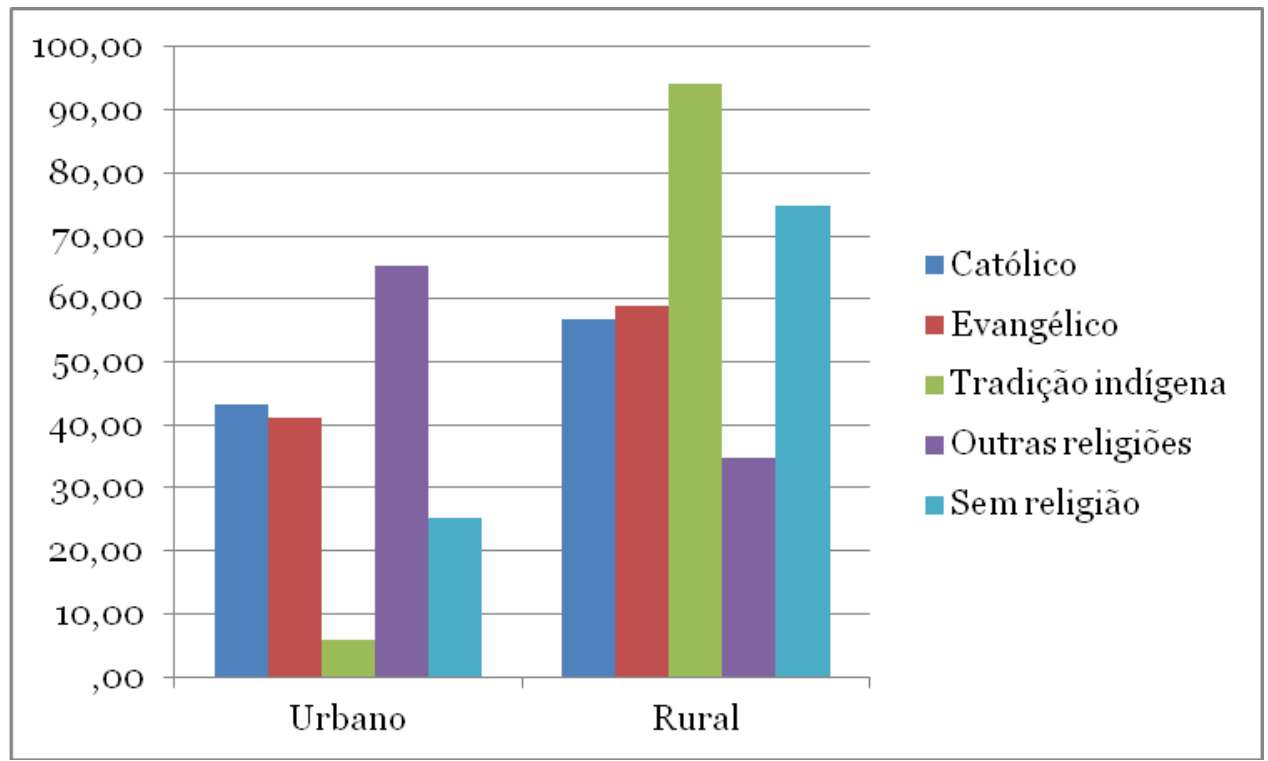

Fonte: Censo Demográfico 2010, IBGE.

\section{b. Religião e estrutura etária entre a população autodeclarada indígena no Brasil}

Segundo dados apresentados no Gráfico 4, o catolicismo apresenta um aumento gradual com o aumento da idade. Por outro lado, os evangélicos apresentam uma distribuição praticamente igual entre os grupos etários. Outro fato que chama a atenção é o declínio no número de indivíduos que declararam ter religiões de tradição indígena à medida que aumenta a idade do grupo etário. $\mathrm{O}$ 
mesmo fenômeno também é observado em relação aos indivíduos que declararam não ter religião.

\section{Gráfico 4 - Denominação religiosa entre a população autodeclarada indígena segundo grupo etário (\%) 2010}

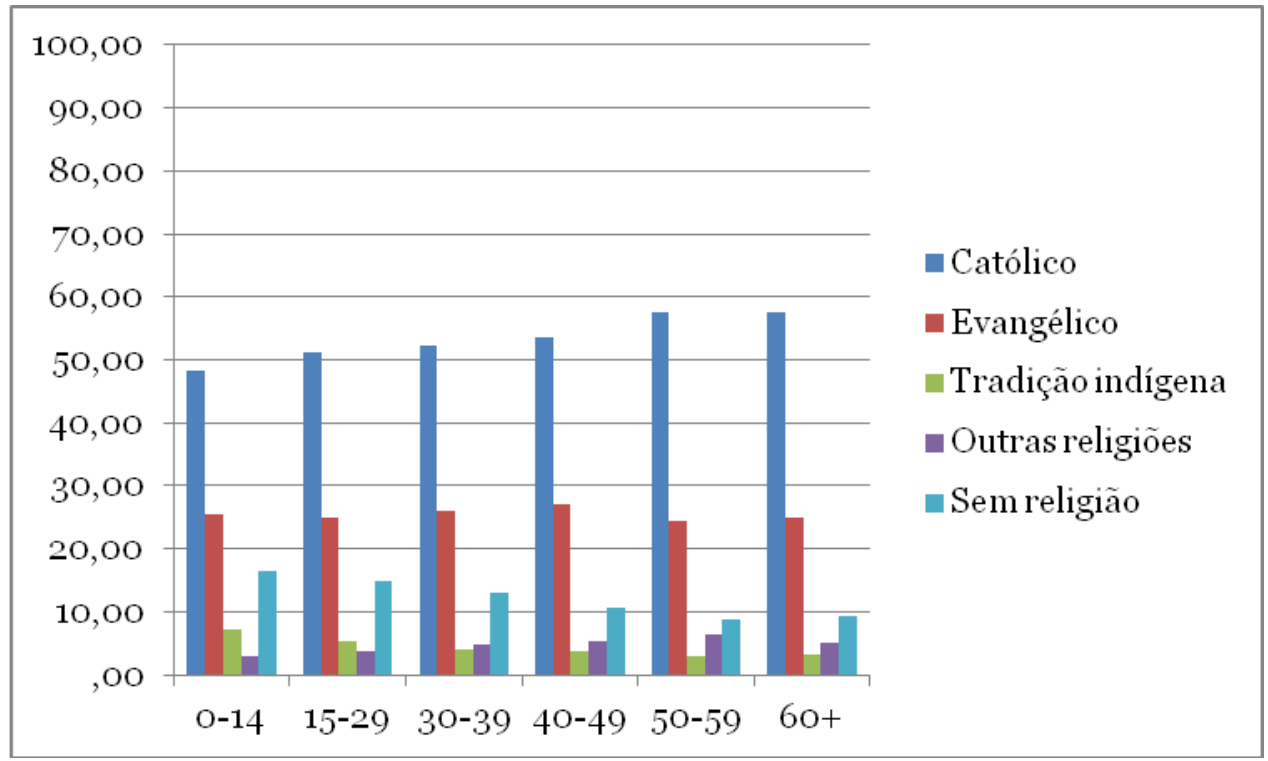

Fonte: Censo Demográfico 2010, IBGE.

\section{c. Religião e escolaridade entre a população autodeclarada indígena no Brasil}

Como pode ser observado no Gráfico 5, de uma maneira geral, independentemente da denominação religiosa, os autodeclarados indígenas apresentaram uma escolaridade relativamente baixa, com destaque para os que têm como religião as tradições indígenas e os sem religião. Outro ponto a ser destacado é que os católicos e evangélicos apresentam um perfil escolar idêntico, com mais de 60\% da população com até sete anos de estudo. Por outro lado, o grupo "outras religiões" apresentou o maior percentual de pessoas com alta escolaridade. 


\section{Gráfico 5 Denominação religiosa entre a população autodeclarada indígena segundo anos de estudo (\%) 2010}

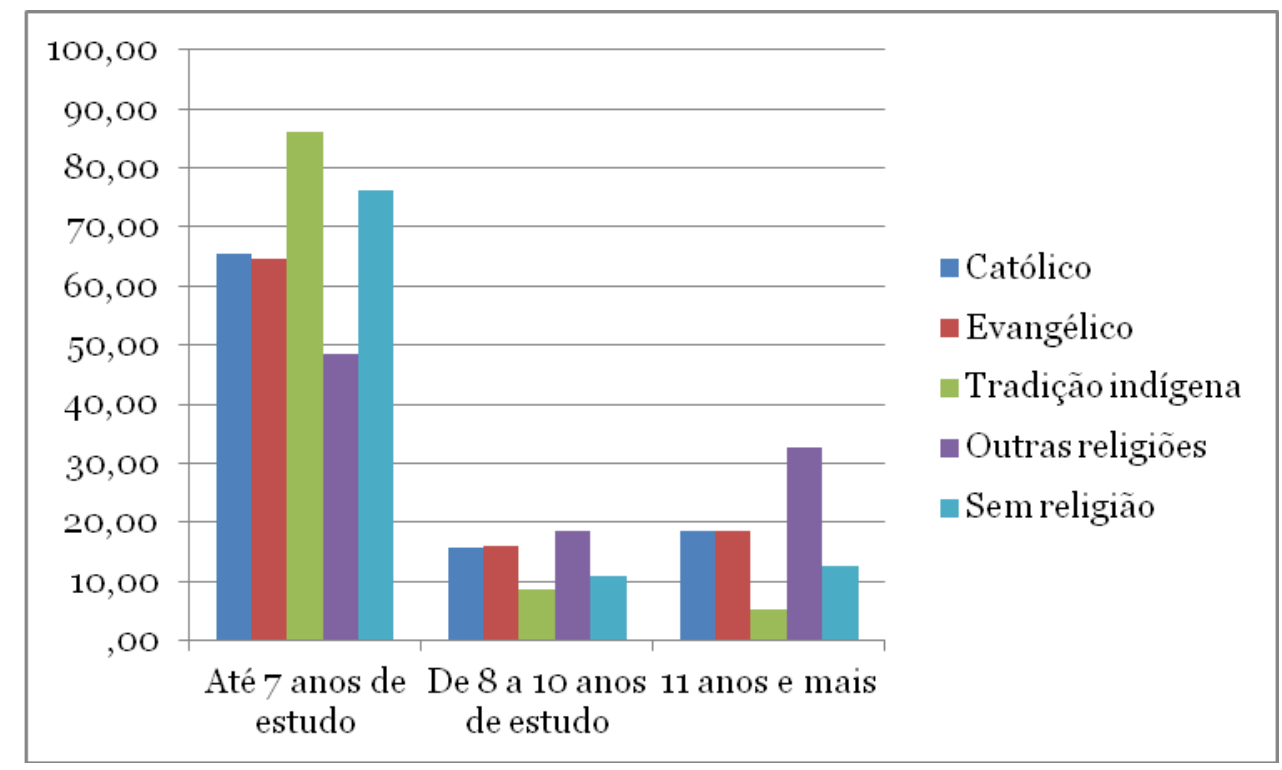

Fonte: Censo Demográfico 2010, IBGE.

\section{d. Denominação religiosa entre os autodeclarados indígenas nos dez municípios com o maior percentual de indígenas no Brasil}

Neste tópico foram selecionados os municípios com o maior percentual de indígenas para se observar, em um ambiente onde eles são maioria, como se comporta a distribuição das denominações religiosas. Como pode ser observado na Tabela 1, sete municípios se localizam na região Norte, dois na região Nordeste e um na região Sudeste. Apenas em dois municípios (Amajari-RR e Pacaraíma-RR, na região Norte) a religião católica não é maioria absoluta. Em cinco municípios o percentual de católicos é muito superior ao observado no Brasil. Outros municípios que chamam a atenção são Santa Isabel do Rio Negro-AM com 30\% da população indígena sem religião e Amajari-RR com 37,5\% da população com religião baseada nas tradições indígenas. Por outro lado, também se destaca o fato de que cinco municípios não apresentaram pessoas cuja religião seja de "tradições indígenas", e, em outros três, essas pessoas eram de menos de $1 \%$. 


\section{Tabela 1 - Dez municípios com maior percentual dautodeclarados indígenas segundo denominação religiosa (\%). 2010.}

\begin{tabular}{|c|c|c|c|c|c|c|}
\hline \multirow{2}{*}{ Região } & Municípios & Católico & Evangélico & $\begin{array}{c}\text { Tradição } \\
\text { indígena }\end{array}$ & $\begin{array}{c}\text { Outras } \\
\text { religiões }\end{array}$ & $\begin{array}{c}\text { Sem } \\
\text { religião }\end{array}$ \\
\hline \multirow{7}{*}{ Norte } & Santa Rosa do Purus-AC & 65,9 & 16,9 & 0,3 & 1,3 & 15,7 \\
\cline { 2 - 7 } & $\begin{array}{c}\text { Santa Isabel do Rio Negro- } \\
\text { AM }\end{array}$ & 60,4 & 8,6 & 0,3 & 0,6 & 30,1 \\
\cline { 2 - 7 } & São Gabriel da Cachoeira- & 73,3 & 23,7 & 0,2 & 2,6 & 0,3 \\
\cline { 2 - 7 } & AM & 45,9 & 13,0 & 37,5 & 2,8 & 0,8 \\
\cline { 2 - 7 } & Normajari-RR & 68,7 & 26,1 & 0,0 & 2,2 & 3,1 \\
\cline { 2 - 7 } & Pacaraíma-RR & 49,7 & 27,1 & 0,0 & 13,8 & 9,5 \\
\cline { 2 - 7 } Nordeste-RR & Uiramutã-RR & 71,8 & 13,2 & 8,9 & 1,6 & 4,5 \\
\cline { 2 - 7 } & Baía da Traição-PB & 76,3 & 14,7 & 0,0 & 1,3 & 7,7 \\
\hline Sudeste & Marcação-PB & 82,8 & 11,3 & 0,0 & 0,4 & 5,4 \\
\hline
\end{tabular}

Fonte: Censo Demográfico 2010, IBGE.

\section{Breves considerações}

Os dados sobre a religião entre a população autodeclarada indígena trazem à luz informações importantes e muitas questões ainda sem respostas.

Primeiramente, é importante destacar que se entre 1991 e 2000 houve um aumento significativo da população indígena no Brasil (a população total passou de 274 mil para 734 mil em nove anos), no decênio posterior, 2000/2010, o crescimento foi muito menos intenso, uma vez que o total de indígenas contabilizado pelo IBGE foi de 818 mil. No período de 1991/2000, o crescimento observado evidencia o aumento dos autodeclarados indígenas via reclassificação racial (MCSWEENEY; ARPS, 2005). Já o aumento populacional observado nos dados de 2010 ainda precisam ser analisados para determinar qual ou quais fatores foram responsáveis, se apenas a dinâmica demográfica e/ou a reclassificação racial. 
Em segundo lugar, é importante ressaltar o perfil cristão desta população. Com destaque para o percentual significativo de evangélicos. Comparando com os dados para o Brasil, o número de evangélicos entre os indígenas é maior. O caso da região Centro-Oeste é emblemático. As duas corentes do cristianismo quase empatam, em termos percentuais (30\%), o que demonstra, por um lado a diminuição e/ou pouca entrada do catolicismo entre os indígenas nesta região, e a grande penetração dos evangélicos. Além desta característica, o que chama a atenção é o elevado percentual de pessoas sem religião. Nas áreas rurais tanto as religiões de tradições indígenas quanto as pessoas sem religião são a maioria. Além dessas características, nas áreas rurais os evangélicos apresentam um percentual maior que os católicos. São também os indivíduos com religiões de tradições indígenas e pessoas sem religião maioria no grupo com menor escolaridade. Ao analisar os dados dos dez municípios com maior parcela de indígenas no Brasil, diversas questões são suscitadas, como a ausência das religiões de tradição indígena em quase todos.

\section{Conclusão}

De uma maneira geral, os dados mostram que entre os indígenas o campo religioso é bastante distinto da população em geral, mas o que chama mais atenção é o grande percentual de pessoas sem religião. Essa realidade suscita uma pergunta: por que os indígenas apresentam percentual significativo de pessoas que não se identificam com nenhuma religião? O que realmente significa ser "sem religião" entre os indígenas? Tal constatação sugere a necessidade de novos estudos para entender esse fenômeno. Sem dúvida são necessários estudos de cunho etnográfico, mas também vale destacar que é possível buscar respostas no próprio Censo 2010, uma vez que algumas variáveis, como língua falada, etnia e local de residência (Terra Indígena) podem garantir uma aproximação maior dos dados estatísticos com particularidades culturais e mostrar caminhos a serem percorridos para entender o fenômeno religioso entre os indígenas. Esta tarefa é um desafio para a demografia brasileira, que historicamente tem deixado de lado os indígenas em suas análises, ainda mais em se tratando do fenômeno religioso. 


\section{REFERÊNCIAS}

ALVES, J. E. D.; BARROS, L.F.W.; CAVENAGHI, S. A dinâmica das filiações religiosas no Brasil entre 2000 e 2010: diversificação e processo de mudança de hegemonia. Rever - PUC-SP, São Paulo, v. 12, p. 145-174, 2012.

COUTINHO, R.Z.; GOLGHER, A.B. The changing landscape of religious affiliation in Brazil between 1980 and 2010: age, period, and cohort perspectives. Revista Brasileira de Estudos da População, Rio de Janeiro, v.31, n.1, p. 73-98, 2014.

DIAS JUNIOR, C.S.; VERONA, A.P.A.; PENA, J. L.; MACHADO-COELHO, G. L. L. Desigualdades Demográficas e Socioeconômicas entre Brancos e Indígenas no Brasil. Redes, Santa Cruz do Sul, v. 15, p. 50-65, 2010.

INSTITUTO BRASILEIRO DE GEOGRAFIA E ESTATÍSTICA - IBGE. Os indígenas no Censo Demográfico 2010, Rio de Janeiro: IBGE, 2012.

MCKINNON, S.; POTTER, P.; GARRARD-BURNETT, V. Adolescent fertility and religion in Rio de Janeiro, Brazil in the year 2000: the role of Protestantism. Population Studies, Philadelphia, v. 62, n.3, 2008, p. 289-303.

MCSWEENEY, K; ARPS, S.A. Demographic turnaround" The rapid growth of indigenous populations in lowland Latin America. Latin America Research Review, Pittsburgh, v.40, n.1. 3-29, 2005.

OGLAND, C.; SUNIL, T.S.; BARTKOWSKI, J.P.; XU, X. Religious Influences on Teenage Childbearing among Brazilian Female Adolescents Journal for the Scientific Study of Religion, Indianapolis, v.49, n.4, p.754-760, 2010.

OGLAND, C.; VERONA, A.P. Religion and the Rainbow Struggle: Examining the Role of Religion in Attitudes toward Homosexuality and Same-Sex Civil Unions in Brazil. Journal of Homosexuality, New York, v.61, p. 99-115, 2014.

PAGLIARO, H; AZEVEDO, M.M; SANTOS, R.V. (Org.) Demografia dos povos indígenas no Brasil. Rio de Janeiro: Editora Fiocruz, 2005.

POTTER, J.; AMARAL, E.; WOODBERRY, R. The Growth of Protestantism in Brazil and Its Impact on Male Earnings, 1970-2000, Social Forces, Chapel Hill, v.o, n.o, p.1-29, 2014.

SMITH, C. Theorizing religious effects among American adolescents. Journal for the scientific study of religion, Indianapolis, v. 41, n.1, p.17-30, 2003.

VERONA , A.P.A. Sexual Initiation and religion in Brazil. Tese. (Doutorado em Sociologia). The University of Texas at Austin, 2010. 
VERONA, A.P.A. Explanations for religious influence on adolescent sexual behavior in Brazil: direct and indirect effects. Revista Brasileira de Estudos de População, Rio de Janeiro, v. 28, n. 1, p.187-201, 2011.

VERONA, A.P.A.; DIAS JÚNIOR, C.S. Religião e fecundidade entre adolescentes no Brasil. Revista Panamericana de Salud Pública (Impresa) / Pan American Journal of Public Health (Impresa), Danvers, v. 31, p. 25-31, 2012.

VERONA, A.P.A; HUMMER, R.; DIAS JUNIOR, C.S; LIMA, L.C Infant mortality and mothers' religious involvement in Brazil. Revista Brasileira de Estudos de População, Rio de Janeiro, v.27, n.1, p. 59-74, 2010.

WRIGHT, R.M. (Org.) Transformando os Deuses - Igrejas evangélicas, pentecostais e neopentecostais entre os povos indígenas no Brasil. Campinas: Editora Unicamp, 2004. 


\section{Anexo 1}

Censo Demográfico 2010 - IBGE:

Composição dos grupos de religião

\section{OO SEM RELIGIÃO}

ooo Sem religião

o01 Agnóstico

002 Ateu

\section{CATÓLICA APOSTÓLICA ROMANA}

110 Católica Apostólica Romana

111 Católica Carismática; Católica Pentecostal

112 Católica Armênia; Católica Ucraniana

\section{CATÓLICA APOSTÓLICA BRASILEIRA}

120 Católica Apostólica Brasileira

\section{CATÓlica ORTODOXA}

130 Católica Ortodoxa

\section{ORTODOXA CRISTÃ}

140 Ortodoxa Cristã

149 Outras ortodoxas cristãs

\section{OUTRAS CATÓLICAS}

199 Outras católicas

\section{EVANGÉLICA DE MISSÃO LUTERANA}

210 Igrejas Luteranas

219 Outras evangélicas de missão luterana

\section{EVANGÉLICA DE MISSÃO PRESBITERIANA}

220 Igreja Evangélica Presbiteriana

221 Igreja Presbiteriana Independente

222 Igreja Presbiteriana do Brasil

223 Igreja Presbiteriana Unida

224 Presbiteriana Fundamentalista

225 Presbiteriana Renovada

229 Outras evangélicas de missão presbiteriana 


\section{EVANGÉLICA DE MISSÃO METODISTA}

230 Igreja Evangélica Metodista

231 Evangélica Metodista Wesleyana

232 Evangélica Metodista Ortodoxa

239 Outras evangélicas de missão metodista

\section{EVANGÉLICA DE MISSÃO BATISTA}

240 Igreja Evangélica Batista

241 Convenção Batista Brasileira

242 Convenção Batista Nacional

243 Batista Pentecostal

244 Batista Bíblica

245 Batista Renovada

249 Outras evangélicas de missão batista

\section{EVANGÉLICA DE MISSÃO CONGREGACIONAL}

250 Igreja Evangélica Congregacional

251 Igreja Congregacional Independente

259 Outras evangélicas de missão congregacional

\section{EVANGÉLICA DE MISSÃO ADVENTISTA}

260 Igreja Evangélica Adventista do Sétimo Dia

261 Igreja Evangélica Adventista Movimento de Reforma

262 Igreja Evangélica Adventista da Promessa

269 Outras evangélicas de missão adventista

\section{EVANGÉLICA DE MISSÃO EPISCOPAL ANGLICANA}

270 Igreja Evangélica Episcopal Anglicana

279 Outras evangélicas missão episcopal anglicana

\section{EVANGÉLICA DE MISSÃO MENONITA}

280 Igreja Evangélica Menonita

289 Outras evangélicas de missão menonita

\section{3o EXÉRCITO DA SALVAÇÃO}

300 Exército da Salvação

\section{EVANGÉLICA DE ORIGEM PENTECOSTAL ASSEMBLEIA DE DEUS}

310 Igreja Evangélica Assembleia de Deus

311 Igreja Assembleia de Deus Madureira

312 Igreja Assembleia de Deus de Todos os Santos

319 Outras evangélicas de origem pentecostal assembleia de Deus 


\section{EVANGÉLICA DE ORIGEM PENTECOSTAL CONGREGAÇÃO CRISTÃ DO}

\section{BRASIL}

320 Igreja Congregação Cristã do Brasil

329 Outras evangélicas de origem pentecostal congregação cristã do Brasil

\section{EVANGÉLICA DE ORIGEM PENTECOSTAL O BRASIL PARA CRISTO}

330 Igreja Evangélica Pentecostal O Brasil para Cristo

339 Outras evangélicas de origem pentecostal o Brasil para Cristo

\section{EVANGÉLICA DE ORIGEM PENTECOSTAL EVANGELHO \\ QUADRANGULAR}

340 Igreja Evangelho Quadrangular

349 Outras evangélicas de origem pentecostal evangelho quadrangular

\section{EVANGÉLICA DE ORIGEM NEOPENTECOSTAL UNIVERSAL DO REINO}

\section{DE DEUS}

350 Igreja Universal do Reino de Deus

359 Outras evangélicas de origem neopentecostal universal do reino de Deus

\section{EVANGÉLICA DE ORIGEM PENTECOSTAL CASA DA BÊNÇÃO}

360 Igreja Evangélica Casa da Bênção

369 Outras evangélicas de origem pentecostal casa da bênção

37 EVANGÉLICA DE ORIGEM PENTECOSTAL CASA DE ORAÇÃO

370 Igreja Evangélica Casa de Oração

379 Outras evangélicas de origem pentecostal casa de oração

38 EVANGÉLICA DE ORIGEM PENTECOSTAL DEUS É AMOR

380 Igreja Evangélica Pentecostal Deus é Amor

389 Outras evangélicas de origem pentecostal Deus é amor

39 EVANGÉLICA DE ORIGEM NEOPENTECOSTAL MARANATA

390 Igreja Evangélica Pentecostal Maranata

399 Outras evangélicas de origem neopentecostal maranata

4O EVANGÉLICA RENOVADA NÃO DETERMINADA

400 Evangélica renovada, restaurada e reformada não determinada

401 Pentecostal renovada, restaurada e reformada não determinada

409 Outras evangélicas renovadas não determinadas

42 EVANGÉLICA DE ORIGEM PENTECOSTAL COMUNIDADE CRISTÃ 420 Igreja Evangélica Comunidade Cristã

429 Outras evangélicas de origem pentecostal comunidade cristã 


\section{EVANGÉLICA DE ORIGEM PENTECOSTAL NOVA VIDA}

430 Igreja de Origem Pentecostal Nova Vida

439 Outras evangélicas de origem pentecostal nova vida

\section{EVANGÉLICA DE ORIGEM PENTECOSTAL COMUNIDADE EVANGÉLICA}

440 Igreja Evangélica Comunidade Evangélica

449 Outras evangélicas de origem pentecostal comunidade evangélica

45 OUTRAS IGREJAS EVANGÉLICAS DE ORIGEM PENTECOSTAL

450 Outras Igrejas Evangélicas Pentecostais

451 Igreja Internacional da Graça de Deus

452 Igreja Apostólica Renascer em Cristo

453 Igreja Evangélica Reviver em Cristo

454 Igreja Universal dos Filhos de Deus

455 Igreja Mundial do Poder de Deus

46 EVANGÉLICA DE ORIGEM PENTECOSTAL AVIVAMENTO BÍBLICO

460 Igreja Pentecostal Avivamento Bíblico

469 Outras evangélicas de origem pentecostal avivamento bíblico

47 EVANGÉLICA DE ORIGEM PENTECOSTAL CADEIA DA PRECE

470 Igreja Evangélica Cadeia da Prece

479 Outras evangélicas de origem pentecostal cadeia da prece

\section{EVANGÉLICA DE ORIGEM PENTECOSTAL IGREJA DO NAZARENO}

480 Igreja do Nazareno

489 Outras evangélicas de origem pentecostal igreja do Nazareno

\section{EVANGÉLICA NÃO DETERMINADA}

490 Evangélica não determinada

492 Declaraçãomúltipla de religião evangélica

499 Outras evangélicas

\section{IGREJA DE JESUS CRISTO DOS SANTOS DOS ÚLTIMOS DIAS}

510 Igreja de Jesus Cristo dos Santos dos Últimos Dias/Mórmons

519 Outras igrejas de Jesus Cristo dos santos dos últimos dias

\section{EVANGELICOS TESTEMUNHA DE JEOVÁ}

520 Testemunha de Jeová

529 Outros evangélicos testemunha de Jeová

53 LBV/RELIGIÃO DE DEUS

530 Legião da Boa Vontade/Religião de Deus 


\section{ESPIRITUALISTA}

590 Espiritualista

599 Outras espiritualistas

\section{ESPÍRITA}

610 Espírita, Kardecista

619 Outras Espíritas

\section{UMBANDA}

620 Umbanda

629 Outras umbandas

\section{CANDOMBLÉ}

630 Candomblé

639 Outros candomblés

\section{OUTRAS DECLARAÇÕES DE RELIGIOSIDADE AFRO-BRASILEIRA}

640 Religiosidades afro-brasileiras

641 Declaração múltipla de religiosidade afro com outras religiosidades

649 Outras declarações de religiosidade afro-brasileira

\section{JUDAÍSMO}

710 Judaísmo

711 Essenismo

719 Outros judaísmos

\section{HINDUÍSMO}

740 Hinduísmo

741 Ioga

749 Outros hinduísmos

\section{BUDISMO}

750 Budismo

751 Nitiren

752 Budismo Theravada

753 Zen Budismo

754 Budismo Tibetano

755 SokaGakkai

759 Outros budismos 


\section{NOVAS RELIGIÕES ORIENTAIS}

760 Igreja Messiânica Mundial

761 SeichoNo-Ie

762 Perfect Liberty

763 Hare Krishna

764 Discípulosde Osho

765 Tenrykyo

766 Mahicari

\section{OUTRAS RELIGIÕES ORIENTAIS}

790 Religiões Orientais

791 Bahai

792 Shintoismo

793 Taoismo

799 Outras religiões orientais

\section{ISLAMISMO}

810 Islamismo

811 Druso

819 Outros Islamismos

\section{TRADIÇÕES ESOTÉRICAS}

820 Esotérica

821 Racionalismo Cristão

829 Outras esotéricas

\section{TRADIÇÕES INDÍGENAS}

830 Tradições Indígenas

831 Santo Daime

832 União do Vegetal

833 A Barquinha

834 Neoxamânica

839 Outras indígenas

\section{RELIGIOSIDADE CRISTÃ NÃO DETERMINADA}

850 Religiosidade cristã não determinada 


\section{NÃO DETERMINADA E MÚLTIPLO PERTENCIMENTO}

890 Religiosidade não determinada ou mal definida

891 Declaração múltipla de religiosidade católica/outras religiosidades

892 Declaração múltipla de religiosidade evangélica/outras religiosidades

893 Declaração múltipla de religiosidade católica/espírita

894 Declaração múltipla de religiosidade católica/umbanda

895 Declaração múltipla de religiosidade católica/candomblé

896 Declaração múltipla de religiosidade católica/kardecista

\section{NÃO SABIAM E SEM DECLARAÇÃO}

990 Não sabiam

999 Sem declaração 